\title{
A new mobile and portable scanning lidar for profiling the lower troposphere
}

\author{
C.-W. Chiang ${ }^{1,3}$, S. K. Das ${ }^{2,3}$, H.-W. Chiang ${ }^{1}$, J.-B. Nee ${ }^{3}$, S.-H. Sun ${ }^{1}$, S.-W. Chen ${ }^{4}$, P.-H. Lin ${ }^{4}$, J.-C. Chu ${ }^{4}$, C.-S. Su ${ }^{4}$, \\ and L.-S. $\mathbf{S u}^{5}$ \\ ${ }^{1}$ Department of Mechanical Engineering, Kun Shan University, Tainan, Taiwan \\ ${ }^{2}$ Indian Institute of Tropical Meteorology, Pune, India \\ ${ }^{3}$ Department of Physics, National Central University, Chungli, Taiwan \\ ${ }^{4}$ Taoyuan County Government Environment Protection Bureau, Taoyuan, Taiwan \\ ${ }^{5}$ EI-LIDAR Corporation Limited, Taichung, Taiwan \\ Correspondence to: C.-W. Chiang (cwchiang@alumni.ncu.edu.tw)
}

Received: 20 February 2014 - Published in Geosci. Instrum. Method. Data Syst. Discuss.: 9 April 2014

Revised: 22 September 2014 - Accepted: 23 January 2015 - Published: 17 February 2015

\begin{abstract}
An in-house developed mobile and portable threedimensional scanning lidar system is discussed in this work. The system uses a stimulated Raman-scattering technique for the continuous observation of atmospheric aerosols, clouds and trace gases. This system has a fast scanning technique with a high-speed data acquisition, and permits the real-time measurement of atmospheric pollutants with the temporal resolution of $1 \mathrm{~min}$. This scanning lidar system provides typical horizontal coverage of about $8-10 \mathrm{~km}$ while scanning; however, in zenith mode, good quality backscattered signals can be from $20 \mathrm{~km}$, depending upon the laser power and sky conditions. This versatile lidar system has also overcome the drawbacks which are popular in the traditional scanning lidar systems such as complicated operation, overlap height between laser beam and telescope field of view In this system, the optical damage is reduced by using an integral coaxial transmitter and receiver. Some of the initial results obtained from the scanning lidar system are also presented. This study shows that boundary-layer structure and land-sea breeze circulation can be resolved from the developed scanning lidar system. The application of this lidar system to measure the pollutants over an industrial area is also discussed.
\end{abstract}

\section{Introduction}

Aerosols, clouds, and trace gases are among the principal atmospheric variables which alter the radiative balance of the earth-atmosphere system. Therefore, over the last several decades, scientists who study the atmosphere have shown great interest in characterizing aerosol, clouds and trace gases to understand their impact on climate change and weather systems (Bach, 1976; Twomey, 1991; Kaufman et al., 2002; Mattis et al., 2004). Various remote sensing techniques are used to have profile measurements of atmospheric variables such as aerosol, clouds and trace gases. The optical remote sensing instruments like light detection and ranging (lidar), which is based on the principle of laser spectroscopy, has been proven to have a great potential to probe earth's atmosphere due to their sensitivity, selectivity and rangeresolved data of meteorological variables and atmospheric constituents (Fredriksson et al., 1981; Muruyama et al., 2001; Ansmann et al., 2003). The lidar system provides real-time monitoring of various atmospheric variables (such as aerosol, cloud, temperature, water vapour, optical depth of particulate matter, etc.) and meteorological processes (boundary-layer growth, aerosol and cloud layering, etc.).

In the last 15 years, various in-house developed lidar systems were set up at the National Central University (NCU), Chung-Li $\left(25^{\circ} \mathrm{N}, 121^{\circ} \mathrm{E}\right)$, Taiwan, to understand the vertical distribution of aerosol (Chiang et al., 2004, 2007, 2008a, b; 2012), cloud (Nee et al., 1998; Das et al., 2009) and other me- 

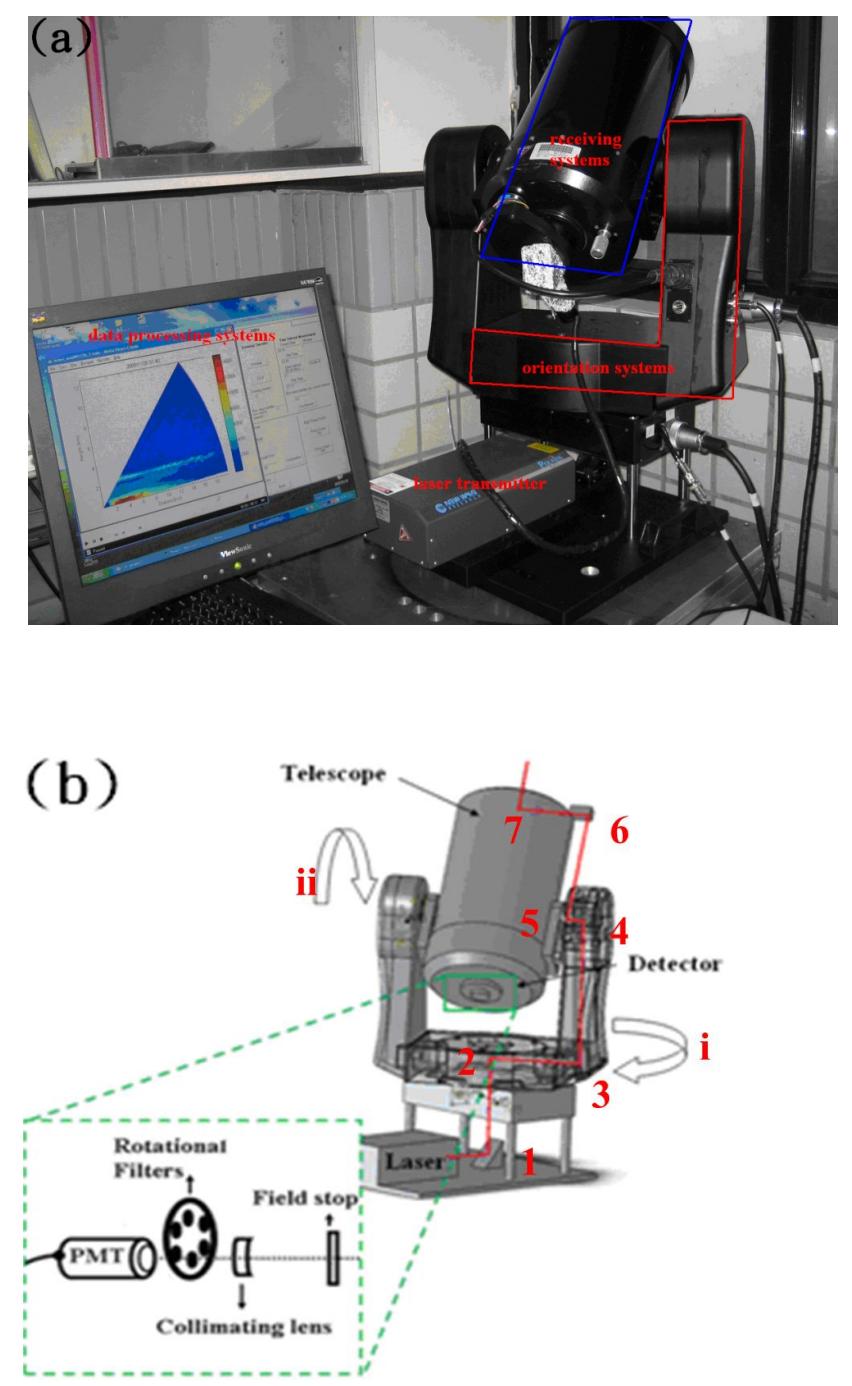

Figure 1. (a) Image and (b) prototype model of the 3-D scanning lidar system. In (b), the arrows (i) and (ii) show the zenith and azimuth scanning direction. Red line shows the path of the transmitting laser beam. The numbers $1-6$ show the position of the reflection mirror. The receiver section is shown in the enlarged box (green).

teorological variables such as temperature (Nee et al., 1995; Chen et al., 2004) and water vapour (Chiang et al., 2009). The NCU lidar system is fixed at the ground and can operate in the nighttime only, which limits the investigation of spatial distribution and the diurnal cycle (associated with orography and atmospheric conditions) of the atmospheric variables.

To understand the variability of aerosol, cloud and trace gases on different scales, both spatially and temporally, lidar techniques are now advancing with the development of powerful computer-controlled instruments. In view of the importance of aerosol and cloud measurements, the threedimensional scanning lidar is the most appropriate and foremost tool to do routine observations automatically (Mayor

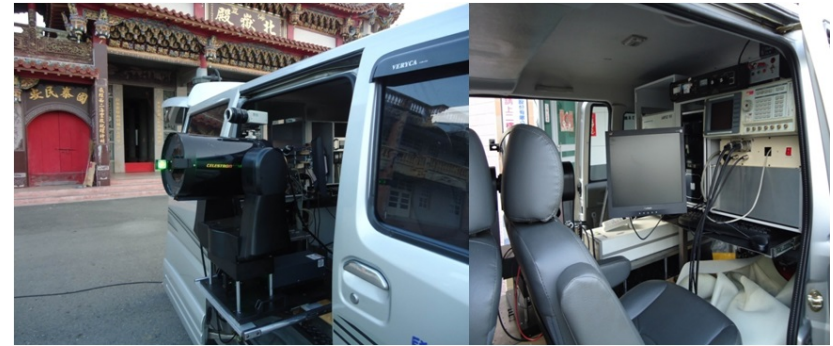

Figure 2. The mobile lidar system and vehicle interior.

and Spuler, 2004; Radlach et al., 2008; Behrendt et al., 2009, 2011). In this context, a mobile and portable threedimensional scanning lidar system has been developed to investigate the properties of aerosol and trace gases in the lower troposphere, which is capable of daytime and nighttime operation. The scanning measurement technique will help in understanding the chemical and physical processes of the atmospheric pollutants caused by the planetary boundary layer (PBL) dynamics/evolution, where the conventional point-sampling instruments are insufficient. This three-dimensional scanning lidar is mobile and portable and have many added advantages over the conventional lidar system.

The purpose of this paper is to report the design of a newly developed scanning lidar with operating features and data analysis techniques. Some of the preliminary results and the potential applications of this scanning lidar are also presented. The paper is presented as follows: the system description and capabilities are discussed in Sect. 2. The methodology and analysis technique are described in Sect. 3. Some of the initial results of the measurements are presented in Sect. 4. Finally, Sect. 5 summarizes the paper.

\section{System description and capabilities}

\subsection{Lidar and auxiliary equipment}

An image and a prototype model of the scanning lidar system are shown in Fig. 1a and b, respectively. The system includes the laser as a transmitter, Schmidt-Cassegrain telescope as a receiver, photomultiplier tube as a detector and real-time data acquisition and signal processing unit. The laser, telescope and scanner are mounted on a vibration-isolated platform (to protect the laser and optical instrument against bumps in mobile application) in an aluminum framework to have a good structural stability. The power supply required for the operation of lidar is met either from commercial mains or a Honda diesel power generator (rating $220 \mathrm{VAC} \pm 10 \%$, $50 \mathrm{~Hz} \pm 10 \%$ ). The lidar system can also be housed in a vehicle, shown in Fig. 2. Technical specifications of the lidar system are given in Table 1 . 
The different Nd:YAG (neodymium:yttrium aluminum garnet)-pulsed solid state lasers are used for different purposes. The commercial Nd:YAG laser (New Wave Polaris) is used as a transmitter for the Rayleigh-Mie lidar system. The laser pulse width is $\sim 10 \mathrm{~ns}$ and repetition rate is adjustable from 10 to $20 \mathrm{~Hz}$. The laser operation is based on the second, third and fourth harmonic frequency generation at 532, 355 and $266 \mathrm{~nm}$, respectively. The in-house developed laser has a pulse energy of about 500, 387, 160 and $95 \mathrm{~mJ}$ at 1064, 532,355 and $266 \mathrm{~nm}$, respectively, and is used as a pumping laser for a Raman lidar (shown in Fig. 3a). The laser beam divergence is about $0.5 \mathrm{mrad}$. The laser is mounted on an optical bench having the facility of height adjustment. Seven reflection mirrors (1-7, shown in Fig. 1b), which are of the thick, hard-coated and flat type, are mounted at $45^{\circ}$ with respect to the lidar system surface to direct the laser beam into the atmosphere. The mirrors have the provision of precise azimuth adjustment and tilting of the laser beam. In case of a breakdown of the laser transmitter, a safety interlock is provided to shut down the laser unit.

The atmospheric species are sensitive to different wavelengths. Therefore, a multi-wavelength laser must be in practice for the measurement of different atmospheric species. To achieve multi-wavelength, the Nd:YAG laser is allowed to pass through various Raman active gases enclosed in a cell. The cell is known as a Raman cell (shown as Fig. 3b) and the method is known as the Raman cell technique. We have locally designed and developed a Raman cell (single pass) of $1.5 \mathrm{~m}$ long and $2 \mathrm{~cm}$ diameter. Two lenses (L1 and L2) are used in the Raman cell. L1 is used at the head of the Raman cell to control the confocal parameter of the pump laser beam. L2 is configured at the end of the cell to collimate the output beam from the Raman cell. The focal length of the input and output cell lenses is about $75 \mathrm{~cm}$. Two similar configurations of the Raman cells are used. The cell is filled with $\mathrm{H}_{2}$ at $5 \mathrm{~atm}$ and pumped with the fourth harmonic $(266 \mathrm{~nm})$ of a Nd:YAG laser generating a wavelength of about $298 \mathrm{~nm}$. The partial pressure of gas in the Raman cell is variable and must be chosen for their better conversion efficiency. Then, another cell is filled with $\mathrm{CH}_{4}$ at $20 \mathrm{~atm}$ and pumped with fourth and third harmonics $(266 / 355 \mathrm{~nm})$ of a Nd:YAG laser generating a wavelength of about 289 and $395 \mathrm{~nm}$, respectively. The transmitted Raman wavelength energy is about 15-30 mJ at 298, 289 and $395 \mathrm{~nm}$. Fast switching of the Raman cells are with the piezoelectric drivers. This allows for the availability of multi-wavelength lidar for simultaneous measurements of several spectral, overlapping atmospheric species. Therefore, the developed lidar system can be also used as a differential absorption lidar (DIAL).

A Schmidt-Cassegrain telescope (Celestron-G8) is used as an optical receiver with a focal length of $f / 10$. The receiver telescope is capable to scan in azimuth (from 0 to $360^{\circ}$ ) and zenith (from 0 to $180^{\circ}$ ) directions through servo motors $\mathrm{i}$ and ii, respectively (Fig. 1b), with a minimum precision of $0.04^{\circ}$. At the back of the telescope there is a colli-
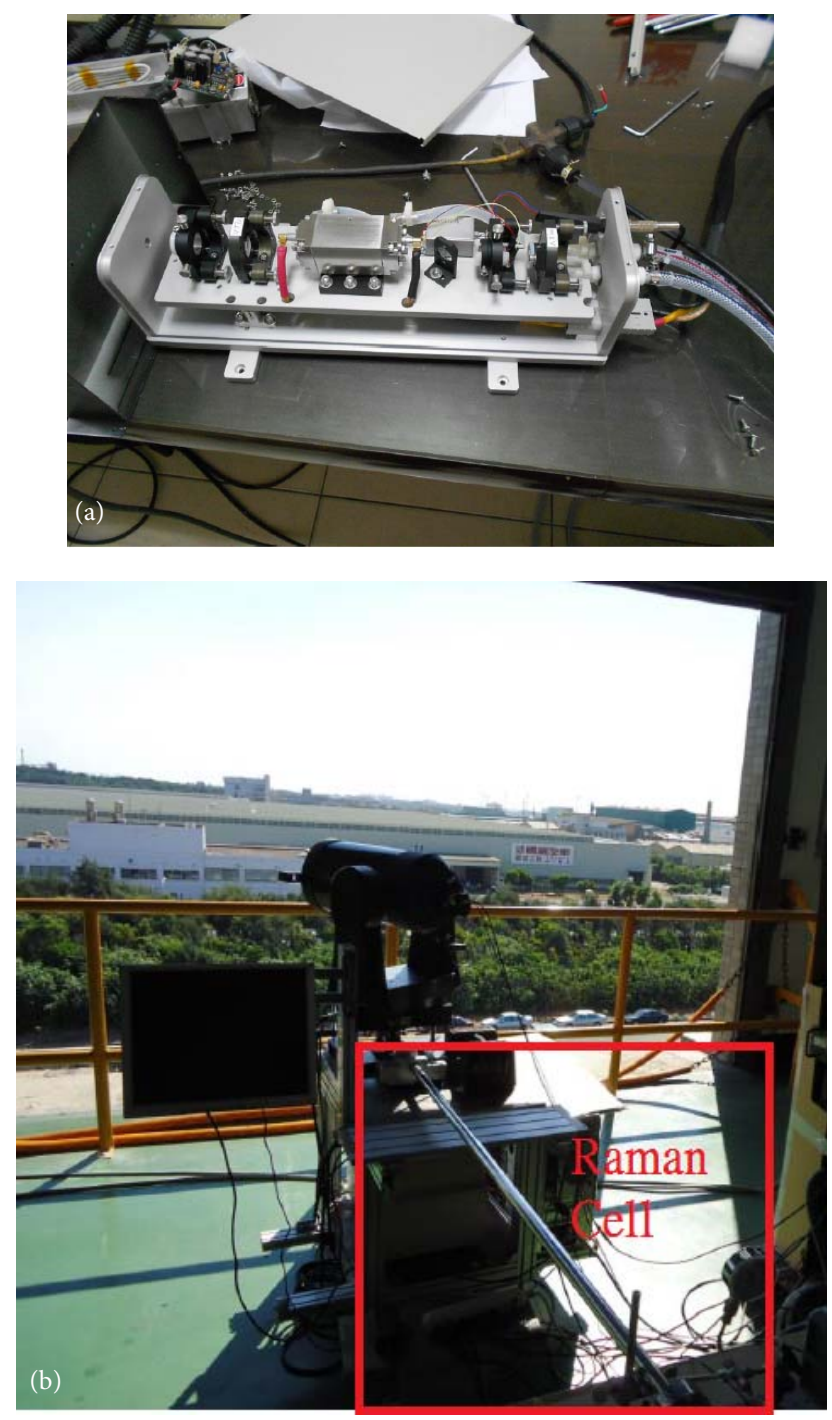

Figure 3. (a) The in-house developed laser $(500 \mathrm{~mJ}$ at $532 \mathrm{~nm})$. (b) Lidar system with the Raman cell (Raman lidar).

mating lens (Fig. 1b), which focuses the entire field of view (FOV) of the telescope onto the photomultiplier tube (PMT, which is used as a detector) head. The background noise level is suppressed by using the narrowband interference filter. Behind the collimating lens, a rotating interference filter wheel (Fig. 1b) is used. The rotating wheel has six filters, which enables the different wavelength selection. The signals from the PMT are fed directly on to a multi-channel transient recorder (Licel TR20-160). The Licel recorder combines an A/D converter (12 bit at $20 \mathrm{MHz}$ ) with $250 \mathrm{MHz}$ fast photon counting system in the acquisition, which allows for a high, dynamic range, louder signal. The spatial and temporal resolution of the data acquisition in the Licel recorder is $7.5 \mathrm{~m}$ and $1 \mathrm{~min}$, respectively.

In the scanning lidar system, a major concern is to maintain the parallel optical axes between telescope and laser 
Table 1. Technical specifications of the scanning lidar.

\begin{tabular}{|c|c|c|}
\hline \multicolumn{3}{|c|}{ Transmitter } \\
\hline Nd:YAG Laser & \multicolumn{2}{|c|}{ New wave Polaris laser In-house developed laser } \\
\hline Wavelength (nm) & \multicolumn{2}{|c|}{$266 / 355 / 532 \mathrm{~nm}$} \\
\hline Pulse energy $(\mathrm{mJ})$ & $10 / 11 / 50 \mathrm{~mJ}$ & $95 / 160 / 387 \mathrm{~mJ}$ \\
\hline Repetition rate $(\mathrm{Hz})$ & $10-20 \mathrm{~Hz}$ & $10 \mathrm{~Hz}$ \\
\hline Beam divergence & \multicolumn{2}{|r|}{$0.5 \mathrm{mrad}$} \\
\hline Pulse duration & \multicolumn{2}{|r|}{$10 \mathrm{~ns}$} \\
\hline Raman cell length & \multicolumn{2}{|r|}{$1.5 \mathrm{~m}$} \\
\hline \multicolumn{3}{|c|}{ Raman output wavelength } \\
\hline $\mathrm{H}_{2}(5 \mathrm{~atm})$ at $266 \mathrm{~nm}$ & & $298 \mathrm{~nm}$ \\
\hline $\mathrm{CH}_{4}(20 \mathrm{~atm})$ at $266 / 355 \mathrm{~nm}$ & & $289 / 395 \mathrm{~nm}$ \\
\hline \multicolumn{3}{|c|}{ Receiver } \\
\hline Telescope type & \multirow{3}{*}{\multicolumn{2}{|c|}{$\begin{array}{c}\text { Schmidt-Cassegrain (Diameter } 20 \mathrm{~cm} \text {; FOV of } 0.5 \mathrm{mrad} \text { ) } \\
\text { Head-on PMT, Hamamatsu R7400 } \\
0.2-3 \mathrm{~nm} \text { FWHM }\end{array}$}} \\
\hline Detector & & \\
\hline Filters & & \\
\hline \multicolumn{3}{|c|}{ Scanner } \\
\hline Scan type & \multirow{2}{*}{\multicolumn{2}{|c|}{$\begin{array}{l}\text { Azimuth-elevation } \\
600-0.25^{\circ} \mathrm{min}^{-1}\end{array}$}} \\
\hline Scan rate & & \\
\hline \multicolumn{3}{|c|}{ Signal processor } \\
\hline Type & \multirow{2}{*}{\multicolumn{2}{|c|}{$\begin{array}{c}\text { Digital processing } \\
250 \mathrm{MHz}\end{array}$}} \\
\hline Sample rate & & \\
\hline
\end{tabular}

beam and make the alignment easier in the process of scanning. The coaxial mode lidar is used to maintain the parallel optical axes between telescope FOV and laser beam, which makes the alignment easier in the process of scanning. However, in most of the scanning lidar where it has a coaxial mode, the backscattered light will be transmitted along the light path. This approach will generate strong background noise in the detector (i.e. PMT) and will limit the detection of backscattered signals. During continuous, long-run lidar operation, the coaxial-mode scanning can damage the detector. Moreover, the complex procedure to guide the emitted laser beam is also inconvenient (Eichinger et al., 1999; McGill et al., 2002).

Our scanning lidar is designed in the coaxial mode to reduce the overlap height $(\sim 260 \mathrm{~m})$ between transmitter and receiver. However, a separate path has been used for the laser transmission. The laser source is kept fixed, but the beam of the laser light (path is indicated by the red line) is made to scan by using seven reflecting mirrors as shown in Fig. 1. All the reflecting mirrors used for the beam steering are numbered 1-7. The laser beam can be steered in both azimuth and zenith directions by rotating the suitable reflecting mirror. This technique helps to protect the laser transmitter from being getting damaged while scanning. In traditional lidar systems, the laser transmitter and telescope rotated together while scanning (Sasano, 1985). This approach can easily damage the laser transmitter, or require frequent calibration for the long-term operation.

All the hardware sections of the lidar system are controlled automatically via a computer with the Microsoft Windows platform. The laser is in auto-control with the computer via an RS232 serial port. The Licel recorder is connected to a computer via a network with TCP/IP (transmission control protocol/Internet protocol) protocol. The servo motors are connected to a computer via GPIB card. The auto-controlled software of lidar has a user-friendly graphical interface that makes the system operation easier (shown in Fig. 4).

\subsection{Experimental set-up and procedure}

The Raman cell technique is used for generating multiwavelength signals. The automatic switching of the Raman cell is through piezoelectric drivers. The rotating filters placed in front of the detector (i.e. PMT) and are automatically controlled via a computer, which allows the lidar system to function as a multi-wavelength lidar.

For pollution measurements, the lidar system can be automatically switched ON depending upon the air quality. This is done by following certain steps: (a) set scan strategy of the lidar system (e.g. scan angle, scan speed, laser power, and temporal and spatial resolution; as shown in Fig. 4), and (b) the rotating zoom camera image recognition system as an early warning (whether to switch ON or not) for the lidar 


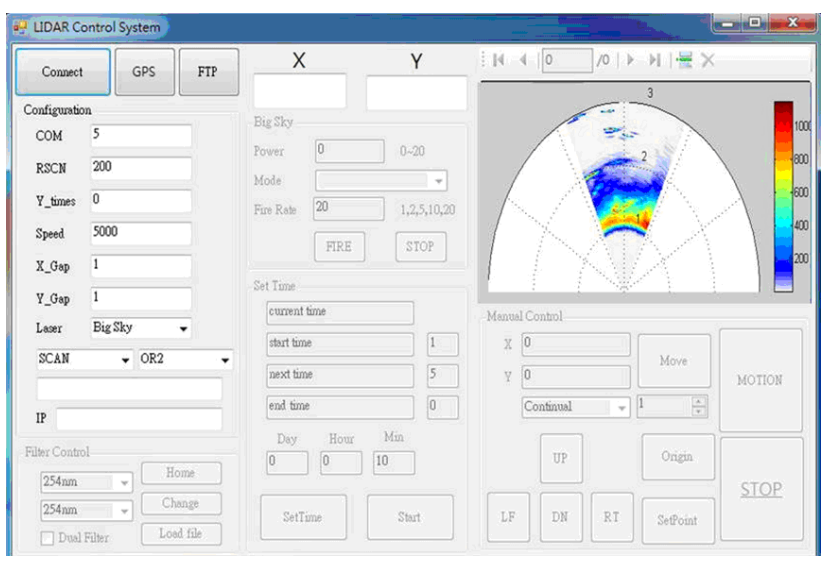

Figure 4. The interface control program of the lidar system.

system. The camera takes a photo and identifies the smoke area. If the intensity of smoke is over the set threshold value, then the lidar transmitter can be triggered and the lidar system will switch ON. The lidar will continue to operate until the air quality improves (i.e. the intensity comes below the set threshold value). All the operations are auto-controlled by a computer.

\section{Methodology and data analysis}

\subsection{Lidar equation}

The optical power measured with lidar is proportional to the signal backscattered by the atmospheric particles and molecules. The detected lidar signal can be expressed as

$P_{\mathrm{M}}(z)=P_{\mathrm{L}} \cdot \frac{O(z) \cdot A_{\mathrm{T}}}{z^{2}} \cdot \beta_{\mathrm{atm}}(z) \cdot e^{-2 \int_{0}^{z} \alpha\left(z^{\prime}\right) \mathrm{d} z^{\prime}}$,

where $P_{\mathrm{M}}$ and $P_{\mathrm{L}}$ are the power received from distance $z$ and laser output energy, respectively; $O(z)$ is the overlap function; $A_{\mathrm{T}}$ is a constant which accounts for system optical efficiency, the telescope receiver area, and the PMT spectral efficiency; and $\beta_{\mathrm{atm}}(z)$ and $\alpha(z)$ are the backscatter and extinction coefficients of the atmosphere, respectively. The integral is taken in between heights 0 and $z$ to derive the atmospheric transmission. The backscattering and extinction coefficients, $\beta_{\text {atm }}(z)$ and $\alpha(z)$ are contributed both from aerosols and air molecules as shown below:

$\beta_{\mathrm{atm}}(z)=\beta_{\mathrm{a}}(z)+\beta_{\mathrm{r}}(z)$,

$\alpha(z)=\alpha_{\mathrm{a}}(z)+\alpha_{\mathrm{r}}(z)$,

where the subscripts " $\mathrm{r}$ " and "a" represent the air molecules and aerosols, respectively.

\subsection{DIAL technique}

The differential absorption lidar (DIAL) technique is based on the signal at two different wavelengths, viz. $\lambda_{\mathrm{ON}}$ and $\lambda_{\mathrm{OFF}}$, corresponding to large and small absorption by the target species, respectively. The DIAL equation for the species concentration estimation is expressed as

$N(z)=\frac{1}{2 \Delta \sigma}\left\{\frac{\mathrm{d}}{\mathrm{d} z}\left[-\ln \frac{P\left(\lambda_{\mathrm{ON}}, z\right)}{P\left(\lambda_{\mathrm{OFF}}, z\right)}\right]+E_{\mathrm{P}}\right\}$,

where $P\left(\lambda_{\mathrm{ON}}, z\right)$ and $P\left(\lambda_{\mathrm{OFF}}, z\right)$ are the return signals from range $z$ at $\lambda_{\mathrm{ON}}$ and $\lambda_{\mathrm{OFF}}$, respectively. $\Delta \sigma=\sigma\left(\lambda_{\mathrm{ON}}\right)-\sigma\left(\lambda_{\mathrm{OFF}}\right)$ is the differential absorption cross section of the measured target species at temperature $T$; and $E_{\mathrm{P}}$ is the correction term for the contribution of differential backscatter and extinction by the aerosols and molecules. Detailed methodology of the DIAL technique for the atmospheric trace gas measurement can be found in Gimmestad (2005, and references therein). We have used $\lambda_{\mathrm{ON}}$ and $\lambda_{\mathrm{OFF}}$ as 289 and $298 \mathrm{~nm}$, respectively for the sulfur dioxide $\left(\mathrm{SO}_{2}\right)$ measurement.

\subsection{Errors and uncertainties}

The sources of errors and uncertainties associated with the measurements of the aerosol backscattering coefficient $\left(\beta_{\mathrm{a}}(z)\right)$ are the noise from the signal, uncertainty in the molecular backscattering coefficient $\left(\beta_{\mathrm{r}}(z)\right)$, consideration of initial value for reference distance and lidar ratio, etc. The signal-to-noise ratio of our lidar system can lead to an uncertainty in $\beta_{\mathrm{a}}(z)$ not exceeding $0.5 \%$. The $\beta_{\mathrm{r}}(z)$, which is calculated using the temperature and density of air derived from the radiosonde data have an uncertainty of within $0.5 \%$ based on Pratt (1985). An uncertainty in the calculation of the lidar ratio is within $30 \%$ and the extinction coefficient is estimated with an error of less than $30 \%$ (Chiang et al., 2008a and references therein).

To evaluate the $\mathrm{SO}_{2}$ measurement errors, the systematic errors from aerosols and other gaseous constituents of the atmosphere, beam misalignment, and statistical errors, etc., must be considered. The error analysis can be referred to in the literature (Schotland, 1974; Vandaele et al., 1994; Fukuchi et al., 1999). In this work, an inaccuracy of less than $30 \%$ was found by comparing the concentration of $\mathrm{SO}_{2}$ recorded between the continuous emission monitoring systems and DIAL technique.

\section{Initial results and discussion}

\subsection{Determination of overlap function with a scanning lidar}

The overlap function of lidar defines the efficiency with which the laser beam is coupled with the receiver FOV as a function of height (Povey et al., 2012, and references 

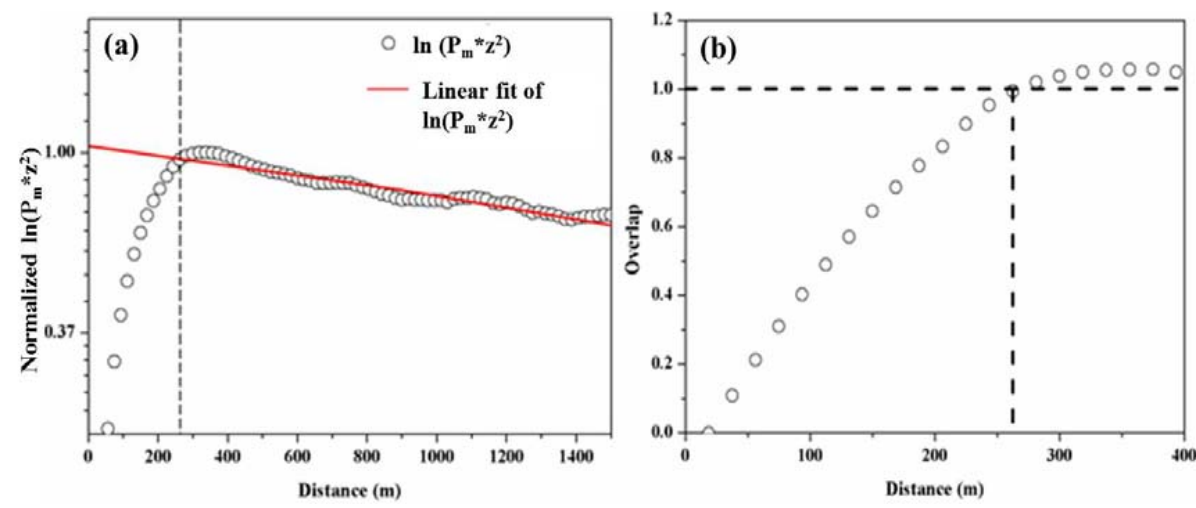

Figure 5. Overlap function determination by keeping the scanning lidar fixed in a horizontal direction. (a) shows a linear fit $\left(y=-2.43 \times 10^{-4} \cdot x+1.03\right.$, shown as a solid red line $)$ applied to the horizontal data $\ln (P m \cdot z 2)$ to determine the expected signal response for the range below overlap height $(\sim 260 \mathrm{~m})$. (b) shows the resultant overlap function obtained from horizontal data $\ln (P m \cdot z 2)$ divided by expected signal.

therein). Accurate estimation of the overlap function describes the accuracy with which the lidar can be used to study the PBL, where the aerosol distribution is inhomogeneous. In a coaxial lidar system, the backscattered signal at short distances is partly blocked by the secondary mirror of the Schmidt-Cassegrain telescope; thus, indicating that the overlap will depend on the spatial intensity distribution of the beam. Therefore, the horizontal operation of lidar can be used to derive the overlap function. The correction is done as $\beta_{\text {atm }}$ and $\alpha$ (see Eq. 1) are assumed to be constant for the horizontal atmospheric path. When there is a complete overlap between transmitter and receiver FOV, the overlap function can be cancelled and the correction function $O(z)$ becomes 1 (Sasano et al., 1979; Campbell et al., 2002). By taking the natural logarithm on the both sides of Eq. (1),

$\ln \left(P_{\mathrm{M}}(z) \cdot z^{2}\right)=\ln \left(P_{\mathrm{L}} \cdot A_{\mathrm{T}} \cdot \beta_{\mathrm{atm}}\right)-2 \alpha \cdot z$.

Because the horizontal atmosphere is assumed to be homogeneous, the term $\left(P_{\mathrm{L}} \cdot A_{\mathrm{T}} \cdot \beta_{\mathrm{atm}}\right)$ becomes constant. Equation (5) describes the expected linear dependence form of the Beer-Lambert relationship, where $-2 \alpha$ is the slope and $\ln \left(P_{\mathrm{L}} \cdot A_{\mathrm{T}} \cdot \beta_{\text {atm }}\right)$ the intercepted coefficients. These linear coefficients are determined by fitting a straight line to $\ln \left(P_{\mathrm{M}}(z) \cdot z^{2}\right)$ over some interval beyond $z$, as shown in Fig. 5. From a linear fit coefficient, the expected signal $\ln \left(P_{\mathrm{M}}(z) \cdot z^{2}\right)$ for a homogeneous path $z<z_{0}(\sim 260 \mathrm{~m})$ can be calculated. $O(z)$ is then determined by normalizing the measured horizontal signal $S_{\mathrm{h}}(z)$ by the expected signal $S_{\mathrm{e}}(z)$

$O(z)=S_{\mathrm{h}}(z) / S_{\mathrm{e}}(z)$.

Figure $5 \mathrm{~b}$ shows the resultant overlap function obtained from the linear fit as shown in Fig. 5a. This result can be used to correct the overlap functions for scanning lidar observation at short distances. The above technique can be applied to re- duce the systematic error in the DIAL system where the overlap height with telescope FOV is different for two different wavelengths.

\subsection{Comparison of extinction coefficient derived from a scanning lidar with particulate matter}

The total mass of aerosols per unit volume is termed particulate matter $(\mathrm{PM})$. The surface pollution indicated by the $\mathrm{PM}_{2.5} / \mathrm{PM}_{10}$ (particulate matter with size smaller than $2 / 10 \mu \mathrm{m}$ ) data are obtained from the Taiwan Environmental Protection Administration (EPA). The EPA monitoring station is about $5 \mathrm{~km}$ away from the lidar site. The $\mathrm{PM}_{2.5} / \mathrm{PM}_{10}$ data are routinely measured by a tapered element oscillating microbalance PM monitor (TEOM model 1400a, R\&P, Albany, NY, USA). Data are collected consecutively on an hourly average for the purpose of legislating, controlling and preventing air pollution.

Figure 6 shows the comparison between the aerosol extinction coefficient derived with lidar at $532 \mathrm{~nm}$ and the aerosol mass concentration (in terms of $\mathrm{PM}_{2.5}$ and $\mathrm{PM}_{10}$ ). The aerosol extinction coefficient derived from the lidar is for every $1 \mathrm{~min}$, while $\mathrm{PM}_{2.5} / \mathrm{PM}_{10}$ is the hourly average data. It is observed that the aerosol extinction coefficient shows good consistency with the PM value. The correlation coefficients between the aerosol extinction coefficient and $\mathrm{PM}_{2.5}$ concentration, and between aerosol extinction coefficient and $\mathrm{PM}_{10}$ concentration are respectively 0.73 and 0.85 . The better correlation between the aerosol extinction coefficient and $\mathrm{PM}_{10}$ concentration may be due to the humidity at our location, which plays a crucial role in the growth of hygroscopic aerosols (Chiang et al., 2008b). 

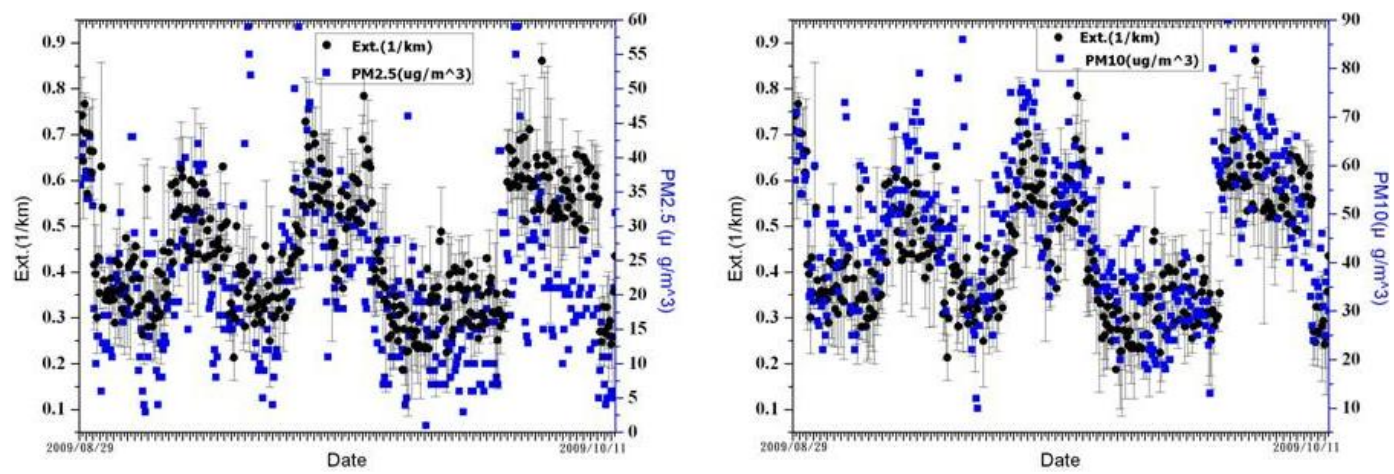

Figure 6. Comparison of (a) $\mathrm{PM}_{2.5}$ and (b) $\mathrm{PM}_{10}$ concentrations with the aerosol extinction coefficient derived from the scanning lidar at $532 \mathrm{~nm}$. The measurements were taken over the Guanyin industrial area during the period from 29 August to 11 October 2009. The PM data are hourly averages; while the lidar data are shown for every $1 \mathrm{~min}$. Error bars indicate the standard deviation of aerosol extinction coefficient.

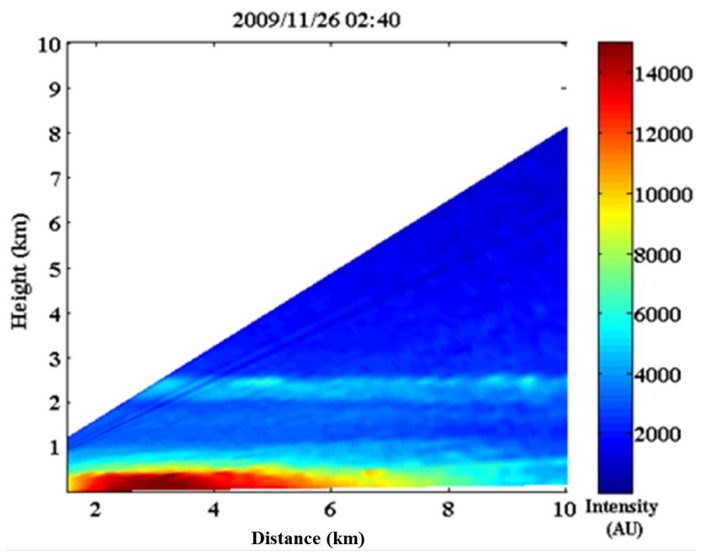

Figure 7. Range height indicator (RHI) plot of the lidar backscattered signal at $532 \mathrm{~nm}$ of the lower troposphere. The lidar measurements were taken at NCU, Chung-Li, on 26 November 2009.

\subsection{Observation of land-sea breeze using a scanning lidar}

The scanning lidar data measured on 26 November 2009, at $02: 40 \mathrm{LT}(\mathrm{LT}=\mathrm{GMT}+8 \mathrm{~h})$ through a vertical scan with a $1^{\circ}$ angular resolution is shown in Fig. 7. The data are averaged for every $10 \mathrm{~min}$ time interval. The figure shows the 2-D lidar backscattered signal intensity representing cross sections of pollutant concentration in the vertical plane. The scanning profiles clearly characterize the well-defined boundary layer. The depth of the boundary layer is about $500 \mathrm{~m}$, which is consistent with the mean height of the PBL $(\sim 580 \mathrm{~m})$ observed over Chung-Li (Chiang et al., 2008b). The aerosol particles were bounded and rather uniformly mixed within the boundary layer.

To investigate the land-sea breeze, the scanning lidar is directed towards the sea, which is about $6.8 \mathrm{~km}$ from the lidar site. It is seen that the lidar site is affected by the land and sea breezes by observing the movement of aerosol structures.
Figure 8 shows the time series contour map of the land breeze (top panel) and the sea breeze (bottom panel). The results are averaged for every $30 \mathrm{~min}$. During the night, it is observed that the backscattered signal increases as the night progresses (refer Fig. 8, top panel). This is possibly due to the increase in aerosol concentrations, humidity, descending boundary layer and/or land breeze onset with the passage of time. Increase in the land breeze may sometimes also lead to increase in the turbulence. In addition, more humid air will blow from the sea towards the land and will get mixed with aerosol, causing the aerosol hygroscopic growth. And the amount of growth is dependent on the hygroscopicity factor. The aerosol hygroscopicity factor causes the strong backscattered signal due to their large cross-section area.

In the morning (see Fig. 8, bottom panel), there is a dense layer near the surface, which is formed by a residual layer at night. This layer rises slowly following the sunrise. This phenomenon is referred as convection. Moreover, the sea breeze, which is flowing in from the sea underneath the land boundary layer also plays a role in lifting the layer.

\subsection{Air pollution measurement $\left(\mathrm{SO}_{2}\right)$}

Figure 9a shows the photograph of the DIAL measurement site NCU, Chung-Li. The inserted box in the figure shows the horizontal observations as a function of range for two different wavelengths used for $\mathrm{SO}_{2}$ measurement. It can be seen that the differential absorption occurred away from the lidar site, more than $1 \mathrm{~km}$. We infer the different absorption is mainly caused by the human activities since our observing site is located in the outskirts, about $2 \mathrm{~km}$ away from the bustling city. The retrieved $\mathrm{SO}_{2}$ concentration (parts per billion) as a function of range is shown in Fig. 9b. Enhanced concentration of $\mathrm{SO}_{2}$ is observed at $\sim 1300$ and $\sim 1800 \mathrm{~m}$. A comparison of $\mathrm{SO}_{2}$ concentrations simultaneously collected on 29 July 2010 between in situ CEMS (continuous emission monitoring systems) instruments and DIAL measurements is shown in Fig. 10. The lidar is kept fixed at $5^{\circ}$ elevation and 

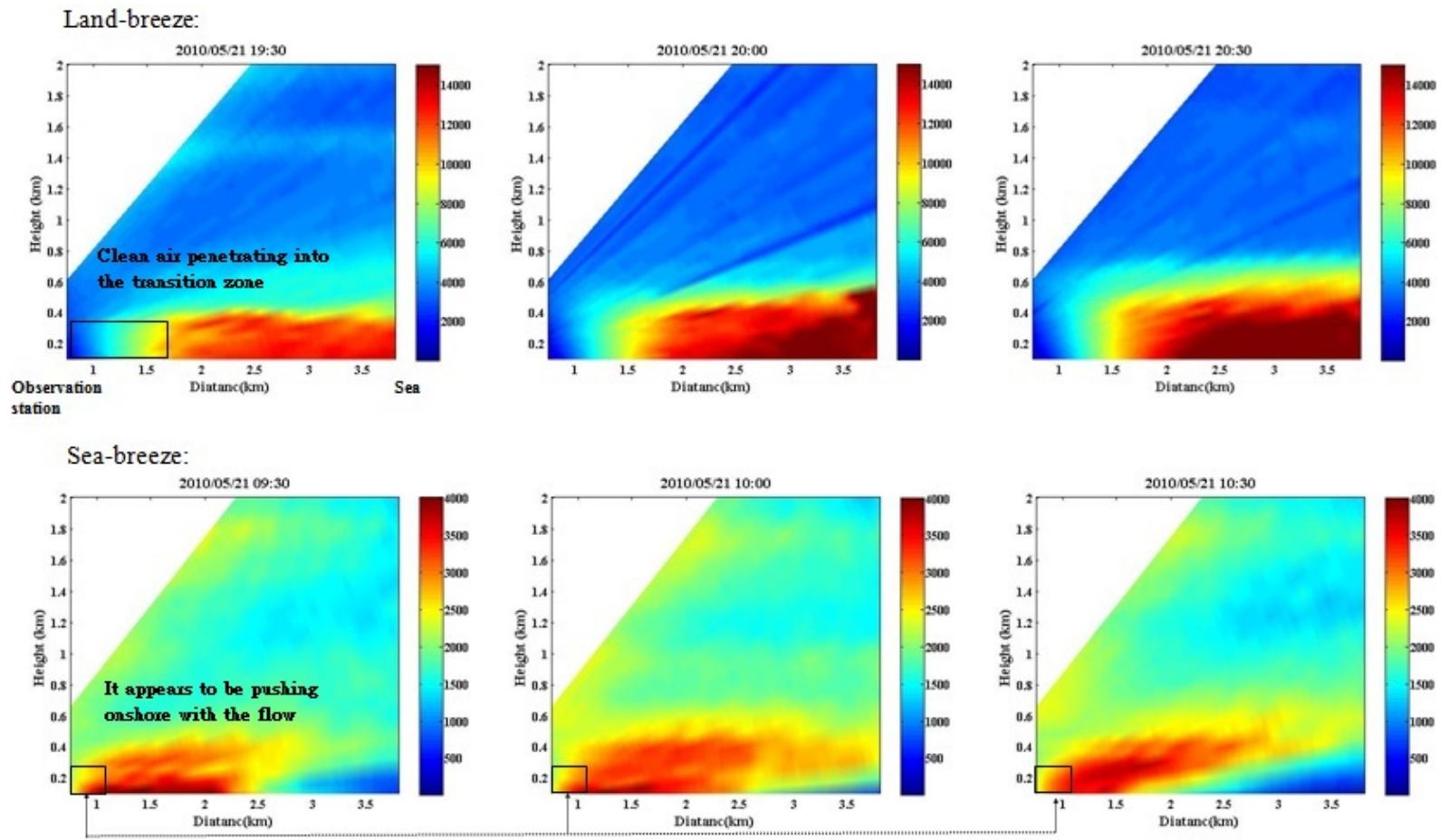

Figure 8. Range height indicator (RHI) plot of lidar backscattered signal at $532 \mathrm{~nm}$ of land (top panels) and sea (bottom panels) breeze cases. The lidar measurements were taken at NCU, Chung-Li, on 21 May 2010.
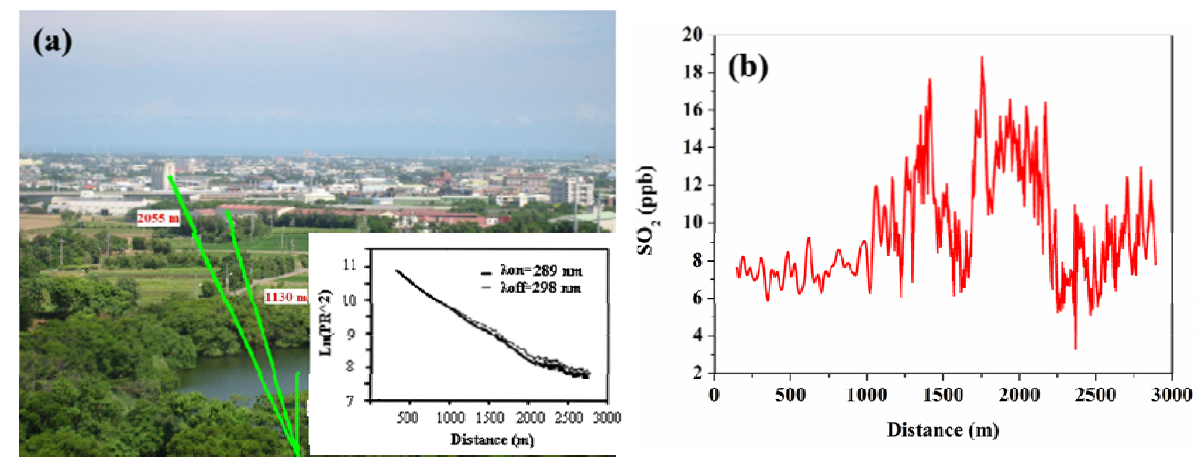

Figure 9. (a) DIAL measurement of $\mathrm{SO}_{2}$ at NCU, Chung-Li, on 7 June 2010. The range-corrected DIAL signal measured at 289 and $298 \mathrm{~nm}$ is shown in the inserted box. (b) The $\mathrm{SO}_{2}$ concentration as a function of range retrieved from the DIAL measurement.

pointed towards the in situ site. Most of the discrepancies in $\mathrm{SO}_{2}$ concentrations derived from the lidar and CEMS measurements are due to the different properties of the instruments or dynamics, or may be due to ventilation of the atmosphere; however, both measurements show a similar tendency.

\subsection{Application of the scanning lidar in monitoring industrial pollutants}

Environmental pollution is one of the major concerns in the modern era, especially in the urban and sub-urban areas. Thus, it is of prime importance to monitor the mass concen- tration of pollutants, their sources and spatial and temporal variations. In this context, the scanning lidar is very useful in order to characterize the plumes or a fugitive emission from the industrial areas and their sources. This could provide information about the areas which can be affected from these particle concentrations. Figure 11 shows a typical example of backscattered signal intensity measured using scanning lidar over the industrial areas at Guanyin in Taoyuan County. The pollutant regions are shown on the topographic map (taken from Google Maps) of the industrial areas. The horizontal scan shows the pollutant covering various emitted sources and concentrations within the targeted scan field. This type of scanned figure can be useful in tracking the source and 


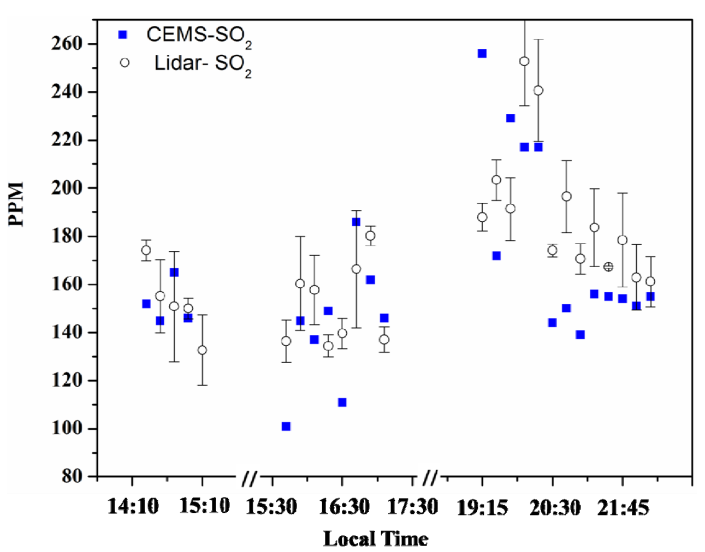

Figure 10. Comparison of $\mathrm{SO}_{2}$ concentrations simultaneously measured from the DIAL and in situ instruments (CEMS) on 29 July 2010 over the Guanyin industrial area. Error bars indicate the statistical $\mathrm{SO}_{2}$ concentration uncertainty derived from the DIAL measurements.

measuring the diffusion range of pollutants within the specified region. This is a useful technique to help the EPA agency to protect the people's health from poor air quality.

\section{Summary}

We have designed and developed a 3-D scanning lidar system for the multi-wavelength measurements of aerosol and trace gases, which will be useful in understanding their temporal and spatial variability. This lidar system is designed with a small size, light weight, and as suitable for installation in various vehicles and therefore will be more handy than the traditional techniques of conducting atmospheric pollutant observations.

The continuous operation of the scanning lidar will gather data, which are useful to examine pollution episodes. Such data are also valuable for understanding the characteristics of pollutant transport, where the conventional point-sampling instruments have limitations. The scanning lidar is a new tool to examine the land-sea breeze circulation and variation of the PBL by observing the movement of aerosol structures.

The set-up of the automatic scanning lidar network will be helpful in the real-time observation of air pollution over the urban and industrial zones. Such network data will help the EPA to protect the people's health and abate the air pollution as quickly as possible. This could also be coupled to future policy directives for air pollution abatement strategies.

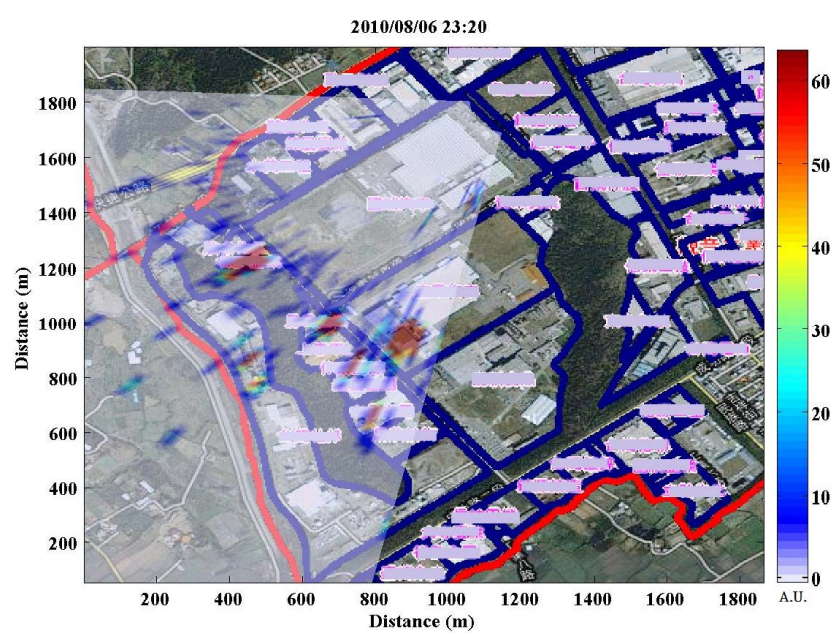

Figure 11. Lidar sector scan at $532 \mathrm{~nm}$ over the Guanyin industrial area on 6 August 2010. The topographical map (Google Maps) have been overlayed.

Acknowledgements. The authors are grateful to the Taiwan EPA for providing the PM data. One of the authors, S. K. Das, was supported by a Taiwan scholarship during this work and would like to acknowledge the Taiwan Government and National Central University, Chung-Li, Taiwan. Comments by two anonymous reviewers and the editor improved earlier versions of this manuscript, for which we are grateful.

Edited by: A.-M. Harri

\section{References}

Ansmann, A., Bösenberg, J., Chaikovsky, A., Comerón, A., Eckhardt, S., Eixmann, R, Freudenthaler, A., Ginoux, P., Komguem, L., Linné, H., Márquez, M. A. L., Matthias, V., Mattis, I., Mitev, V., Müller, D., Music, S., Nickovic, S., Pelon, J., Sauvage, L., Sobolewsky, P., Srivastava, M. K., Stoh, A., Torres, O., Vaughan, G., Wandinger, U., and Wiegner, M.: Long-range transport of Saharan dust to northern Europe: The 11-16 October 2001 outbreak observed with EARLINET, J. Geophys. Res., 108, 4783, doi:10.1029/2003JD003757, 2003.

Bach, W.: Global air pollution and climatic change, Rev. Geophys., 14, 429-474, 1976.

Behrendt, A., Wulfmeyer, V., Riede, A., Wagner, G., Pal, S., Bauer, H., Radlach, M., and Spath, F.: 3-Dimensional observations of atmospheric humidity with a scanning differential absorption lidar, Proc. SPIE, 7475, 74750L, doi:10.1117/12.835143, 2009.

Behrendt, A., Pal, S., Wulfmeyer, V., Valdebenito, B. A. M., and Lammel, G.: A novel approach for the characterization of transport and optical properties of aerosol particles near sources Part I: Measurement of particle backscatter coefficient maps with a scanning UV lidar, Atmos. Environ., 45, 2795-2802, 2011.

Campbell, J. R., Hlavka, D. L., Welton, E. J., Flynn, C. J., Turner, D. D., Spinhirne, J. D., Scott, V. S., and Hwang, I. H.: Full-time, eye-safe cloud and aerosol lidar observation at atmospheric radi- 
ation measurement program sites: Instruments and data processing, J. Atmos. Ocean. Tech., 19, 431-442, 2002.

Chen, W. N., Chiang, C. W., and Nee, J. B.: Lidar ratio and depolarization ratio for cirrus clouds, Appl. Optics, 41, 6470-6476, 2002.

Chen, W. N., Tsao, C. C., and Nee, J. B.: Rayleigh Lidar Temperature Measurements in the Upper Troposphere and Lower Stratosphere, J. Atmos. Sol.-Terr. Phy., 66, 39-49, 2004.

Chiang, C. W., Chen, W. N., Liang, W. A., and Nee, J. B.: Lidar Measurements of Spring Dusts in 2002 at Chung-Li $\left(25^{\circ} \mathrm{N}\right.$, $121^{\circ}$ E), Terr. Atmos. Ocean. Sci., 15, 813-824, 2004.

Chiang, C. W., Chen, W. N., Liang, W. A., Das, S. K., and Nee, J. B.: Optical properties of tropospheric aerosols based on measurements of lidar, sunphotometer, and visibility at Chung-Li $\left(25.1^{\circ} \mathrm{N}, 121.1^{\circ} \mathrm{E}\right)$, Atmos. Environ., 41, 4128-4137, 2007.

Chiang, C. W., Das, S. K., and Nee, J. B.: An iterative calculation to derive extinction-to-backscatter ratio based on lidar extinction measurement, J. Quant. Spectrosc. Ra., 109, 1187-1195, 2008a.

Chiang, C. W., Das, S. K., and Nee, J. B.: Lidar depolarization measurements for aerosol source and property studies over Chungli $\left(24.58^{\circ} \mathrm{N}, 121.1^{\circ} \mathrm{E}\right)$, Atmos. Res., 90, 203-210, $2008 \mathrm{~b}$.

Chiang, C. W., Das, S. K., Nee, J. B., Hu, S. X., and Hu, H. L.: Simultaneous measurement of humidity and temperature in the lower troposphere over Chung-Li, Taiwan, J. Atmos. Sol.-Terr. Phy., 71, 1389-1396, 2009.

Chiang, C. W., Das, S. K., Lin, C. Y., Nee, J. B., Sun, S. H., Chiang, H. W., Yu, M. J., and Zhang, S. T.: Multi-year investigations of aerosol layer using lidar measurements at Chung-Li, Taiwan, J. Atmos. Sol.-Terr. Phy., 89, 40-47, 2012.

Das, S. K., Chiang, C. W., and Nee, J.-B.: Characteristics of cirrus cloud and its radiative properties based on lidar observation Chung-Li, Taiwan, Atmos. Res., 93, 723-735, 2009.

Eichinger, W. E., Cooper, D. I., Forman, P. R., Griegos, J., Osborn, M. A., Richter, D., Tellier, L. L., and Thornton, R.: The development of a scanning Raman water vapor lidar for boundary layer and tropospheric observations, J. Atmos. Ocean. Tech., 16, 1753-1766, 1999.

Fredriksson, K., Galle, B., Nystrom, K., and Svanberg, S.: Mobile LIDAR system for environmental probing, Appl. Optics, 20, 4181-4189, 1981.

Fukuchi, T., Goto, N., Fujii, T., and Nemoto, K.: Error analysis of $\mathrm{SO}_{2}$ measurement by multiwavelength differential absorption lidar, Opt. Eng., 38, 141-145, doi:10.1117/1.602068, 1999.

Gimmestad, G. G.: Differential-absorption lidar for ozone and industrial emissions, in: Lidar - Range-resolved optical remote sensing of the atmosphere, edited by: Weitkamp, C., Springer, New York, 187-212, 2005.

Kaufman, Y. J., Tanre, D., and Boucher, O.: A satellite view of aerosols in the climate system, Nature, 419, 215-224, 2002.
Mattis, I., Ansmann, A., Müller, D., Wandinger, U., and Althausen, D.: Multiyear aerosol observations with dual-wavelength Raman lidar in the framework of EARLINET, J. Geophys. Res., 109, D13203, doi:10.1029/2004JD004600, 2004.

Mayor, S. and Spuler, S.: Raman-shifted eye-safe aerosol lidar, Appl. Optics, 43, 3915-3924, 2004.

McGill, M. J., Hlavka, D. L., Hart, W. D., Spinhirne, J. D., Scott, V. S., and Schmid, B.: The Cloud Physics Lidar: Instrument description and initial measurement results, Appl. Optics, 41, 37253734, 2002.

Murayama, T., Sugimoto, N., Uno, I., Kinoshita, K., Aoki, K., Hagiwara, N., Liu, Z., Matsui, I., Sakai, T., Shibata, T., Arao, K., Sohn, B. J., Won, J. G., Yoon, S. C., Li, T., Zhou, J., Hu, H., Abo, M., Iokibe, K., Koga, R., and Iwasaka, Y.: Ground-based network observation of Asian dust events of April 1998 in east Asia, J. Geophys. Res., 106, 18345-18359, doi:10.1029/2000JD900554, 2001.

Nee, J., Wang, G., Lee, P., and Lin, S.: Lidar studies of particles and temperatures of the atmosphere: First results from National Central University lidar, Radio Sci., 30, 1167-1175, 1995.

Nee, J. B., Len, C. N., Chen, W. N., and Lin, C. T. : Lidar observation of the cirrus cloud in the tropopause at Chung- $\mathrm{Li}\left(25^{\circ} \mathrm{N}\right.$, $121^{\circ}$ E), J. Atmos. Sci., 55, 2249-2257, 1998.

Povey, A. C., Grainger, R. G., Peters, D. M., Agnew, J. L., and Rees, D.: Estimation of a lidar's overlap function and its calibration by nonlinear regression, Appl. Optics, 51, 5130-5143, 2012.

Pratt, R. W.: Review of radiosonde humidity and temperature errors, J. Atmos. Ocean. Tech., 2, 404-407, 1985.

Radlach, M., Behrendt, A., and Wulfmeyer, V.: Scanning rotational Raman lidar at $355 \mathrm{~nm}$ for the measurement of tropospheric temperature fields, Atmos. Chem. Phys., 8, 159-169, doi:10.5194/acp-8-159-2008, 2008.

Sasano, Y.: Observational study on the atmospheric mixed layer and transition layer structures using a Mie lidar, J. Meteorol. Soc. Jpn., 63, 419-435, 1985.

Sasano, Y., Shimizu, H., Takeuchi, N., and Okuda, M.: Geometricalform factor in the laser radar equation: An experimental determination, Appl. Optics, 18, 3908-3910, 1979.

Schotland, R. M.: Errors in the lidar measurement of atmospheric gases by differential absorption, J. Appl. Meteorol., 13, 71-77, 1974.

Twomey, S. A.: Aerosols, clouds and radiation, Atmos. Environ., 25, 2435-2442, 1991.

Vandaele, A. C., Simon, P. C., Guilmot, J. M., Carleer, M., and Colin, R.: $\mathrm{SO}_{2}$ absorption cross section measurement in the UV using a Fourier transform spectrometer, J. Geophys. Res., 99, 25599-25605, 1994. 